\title{
JOURNAL OF \\ Coloproctology
}

NUMBER

OCTOBER / DECEMBER 2011

ORIGINALS ARTICLES

\section{Prognostic impact of the lymph node metastatic ratio on 5-year survival of patients with rectal cancer not submitted to preoperative chemoradiation}

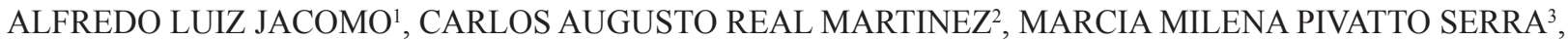 \\ FLÁVIA EMI AKAMATSU ${ }^{4}$, JOSÉ AIRES PEREIRA ${ }^{5}$, MAURO FIGUEIREDO CARVALHO DE ANDRADE 6 , \\ NELSON FONTANA MARGARIDO ${ }^{7}$
}

\begin{abstract}
${ }^{1}$ Associate Professor of Human Structural Topography, Surgery Department of the Medical School of Universidade de São Paulo (USP) - São Paulo (SP), Brazil. ${ }^{2}$ Full Professor, Surgery Department of FMUSP - São Paulo (SP), Brazil; Adjunct Professor, Postgraduate Program in Health Sciences, Universidade São Francisco (USF) - Bragança Paulista (SP), Brazil. ${ }^{3}$ Assistant Professor, Doctor of Statistics, Medical Sciences at USF - Bragança Paulista (SP), Brazil. ${ }^{4}$ Professor and Doctor of Human Structural Topography, Surgery Department of the Medical School of USP - São Paulo (SP), Brazil. ${ }^{5}$ Assistant Professor, Master in Pathology, Medical Sciences at USF - Bragança Paulista (SP), Brazil. ${ }^{6}$ Professor and Doctor of Human Structural Topography, Surgery Department of the Medical School of USP - São Paulo (SP), Brazil. ${ }^{7}$ Full Professor of Human Structural Topography, Medical School of USP - São Paulo (SP), Brazil.
\end{abstract}

JACOMO AL, MARTINEZ CAR, SERRA MMP, AKAMATSU FE, PEREIRA JA, ANDRADE MFCD, MARGARIDO NF. Prognostic impact of the lymph node metastatic ratio on 5-year survival of patients with rectal cancer not submitted to preoperative chemoradiation. J Coloproctol, 2011;31(4):311-324.

ABSTRACT: Lymph node metastases are a major prognostic factor in colorectal cancer. Inadequate lymph node resection is related to shorter survival. The lymph nodes ratio (LNR) has been used as a prognostic factor in patients with colon cancer. Few studies have evaluated the impact of LNR on the 5-year survival of patients with rectal cancer. Objective: To evaluate the impact of LNR on the survival of patients with rectal cancer not submitted to preoperative chemoradiotherapy. Methods: Ninety patients with rectal cancer excluding colon tumors, synchronous tumors, hereditary colorectal cancer and those undergoing preoperative chemoradiation. The patients were divided into three groups according to the LNR: LNR-0, no lymph nodes; LNR-1, 1 to $20 \%$ of compromised lymph nodes; and LNR-2, more than $\mathbf{2 1 \%}$ of compromised lymph nodes. The cutoff identification for the selected sample was obtained from the curve of receiver operating characteristics (ROC). Survival was assessed by Kaplan-Meier test, the difference among groups by Cox-Mantel test and the correlation among variables by Pearson's test, adopting a significance level of $5 \%$ (p $\leq$ 0.05). Results: The 5-year survival was related to the Dukes classification, TNM, number of metastatic lymph nodes and

Study carried out at the LIM-02, Human Structural Topography, Surgery Department of the Medical School of Universidade de São Paulo (USP) - São Paulo (SP), Brazil. Postgraduate Program in Health Sciences, Universidade São Francisco (USF) - Bragança Paulista (SP), Brazil.

Financing source: none.

Conflict of interest: nothing to declare.

$\overline{\text { Submitted on:04/08/2011 }}$

Approved on: 06/09/2011 
LNR. A difference was observed in 5-year survival between the different classes of LNR. Patients classified as LNR-0 had a survival rate of $85 \%$, while classes LNR-1 and LNR-2, 73 and $19 \%$, respectively $(p=0.0001)$. Conclusions: The results showed that the LNR has an impact on 5-year survival of patients with rectal cancer not submitted to neoadjuvant therapy.

Keywords: rectum; colorectal neoplasms; lymph nodes; lymph node excision; survival analysis.

\section{INTRODUCTION}

Colorectal cancer (CRC) is the third most prevalent neoplasm in the world and the second cause of death related to cancer in western countries ${ }^{1}$. Epidemiological studies have shown a 2.4 -fold increase in the incidence of CRC in the oriental countries ${ }^{2}$. In the last two decades, despite the increase in the number of proximal colon tumors, rectal tumors are still more prevalent ${ }^{3}$. Many clinical, histopathological, molecular and genetic variables have been related to overall survival (OS) and disease-free survival (DFS) in patients with $\mathrm{CRC}^{4}$. Despite the importance of all variables, the parietal invasion, the lymph node involvement and the presence of metastases remain as the variables of more power to predict the OS, DFS and guide the adjuvant therapy indication ${ }^{5-7}$.

In 1932, Dukes ${ }^{8}$ developed the first classification system for colorectal (CR) staging. In this system, the different stages of the disease were classified according to the extent of rectal wall involvement and the presence (or not) of lymph node metastases. Later, several alterations were proposed to improve the OS prediction capability of the original classification ${ }^{9,10}$. Today, the TNM system recommended by the AJCC (American Joint Committee on Cancer) and the UICC (International Union Against Cancer), which stages neoplasms based on the tumor-lymph node (LN)-metastasis triad, is the most frequently used worldwide ${ }^{9-11}$. In the TNM system, the patients are divided into groups and subgroups, according to the extent of tumor invasion in the colon wall, presence and number of metastases in the LNs and the involvement of distant organs ${ }^{11}$. Lymph node involvement is determined by using the number of metastatic LNs and subdivided into: N0 for no LN involvement; N1 for metastases in up to three LNs; and N2 for when four or more LNs are taken by neoplasm ${ }^{11}$.

The importance of lymph node involvement in the OS and DFS in CRC can be better evaluated by results of studies showing that $80 \%$ of the patients without metastases in regional LNs survive five years, while only $50 \%$ of those with compromised LNs survive for the same period ${ }^{12}$. The lowest OS of these patients required complementary therapies associated with the surgical treatment to improve these rates, regardless of the number of compromised $\mathrm{LNs}^{4}$. Then, patients with only one compromised LN are submitted to the same complementary treatment protocol as those with more extensive lymph node involvement ${ }^{4}$.

The precise evaluation of the presence of lymp node metastases is possible only when a proper number of LNs is examined ${ }^{5}$. Studies have shown that the DFS and OS in patients with CRC are directly related to the number of examined $\mathrm{LNs}^{12}$. Modern international guidelines recommend that the minimum number of 12 LNs should be analyzed to enable proper staging $^{12-15}$. However, the number of examined LNs in the surgical specimen is influenced by different variables. The number of identified LNs is directly related to the surgeon's experience and practice, the histological technique used in the lymph node recovery (fresh dissection immediately after resection, fat clearing techniques for fast recovery) and the pathologist's experience and patience to identify them ${ }^{16}$. The neoplasm location - colon or rectum - can also influence the number of recovered $\mathrm{LNs}^{17}$. In colon cancer (CC), the number of dissected LNs is usually higher when compared to $\mathrm{CRC}^{18}$. Despite such peculiarities, the international guidelines recommend that the same number of LNs should be studied for a proper CRC staging ${ }^{19}$.

The difficult recovery of the minimum number of LNs in CRS is even more critical when considering that many patients with CRC are submitted to neoadjuvant chemoradiation (NCR) protocols, in which the number of LNs is reduced by around $30 \%$, further increasing the pathologist's uncertainties regarding the correct disease staging ${ }^{20,21}$. A recent study quantifying the number of LNs recovered after the CRC resec- 
tion, comparing patients submitted or not to the NCR, showed that the patients submitted to NCR had the mean value of recovered LNs of 6.29 per examined specimen, while those not submitted to NCR presented 13.5 , i.e., half the minimum number recommended for a precise staging ${ }^{18}$. The importance of a proper lymph node resection is evident with the results of studies showing that the recovery of less than 12 LNs in the surgical specimen is directly related to lower OS and DFS in patients with $\mathrm{CRC}^{22,23}$.

In order to find a variable that could improve the accuracy of staging systems, especially in patients submitted to improper lymph node resection, the incorporation of lymph node ratio (LNR) into staging systems as an additional variable has been proposed ${ }^{24}$. LNR is defined as the relation between the total number of examined LNs and the number of compromised LNs. Initially, the prognostic value of LNR was evaluated in patients with stomach ${ }^{25,26}$, bladder $^{27}$, breast ${ }^{28}$ and pancreas ${ }^{29}$ cancer, presenting correlation with DFS and OS. In patients with gastric cancer submitted to improper lymphadenectomy, LNR presented greater prognostic power when compared to the number of comproimsed LNs, when using the current staging systems $^{25}$. The routine incorporation of LNR into the staging systems was able to reduce the effects of stage migration $^{4,30}$.

Berger et al. ${ }^{31}$ were the first to analyze whether the LNR also related to OS and DFS in patients with CC. They observed that, after the curative resection, the LNR was an important prognostic variable, recommending its use in future studies to analyze adjuvant treatments ${ }^{31}$. Later, a series of studies confirmed the importance of LNR as a prognostic factor in patients with $\mathrm{CC}^{4,5,32-41}$. However, few studies have evaluated the importance of LNR as a variable related to OS in patient with $\mathrm{CRC}^{42-44}$. The evaluation in patients with $\mathrm{CRC}$ is more difficult to be performed, because the patients submitted or not to LNR protocols are usually evaluated as a single group, which influences the number of recovered LNs in the surgical specimen.

It would be interesting to first study the impact of LNR, subdividing the patients into two groups: one of patients submitted and one of patients not submitted to the NCR, to confirm whether the LNR has predictive power in OS in both groups. After that, the impact of LNR on a group of patients with CRC submitted to NCR could be evaluated. However, according to our knowledge, no study has evaluated the impact of LNR on OS in patients with CRC not submitted to NCR. If the LNR had any impact on OS, it could become a useless strategy to minimize the surgeon and the pathologist's concern about substaging. For this reason, the purpose of this study was to evaluate the impact of LNR on OS of patients with CRC not submitted to NCR.

\section{CASE REPORT AND METHOD}

The study was conducted according to all phases established by the Research Ethics Committee of the Universidade São Francisco and requirements of the Research Ethics Council of the Comissão Nacional de Ética em Pesquisa (CONEP), Ministry of Health (Resolution CNS196/96).

This is a retrospective study, a review in the database of the Coloproctology and Pathology Group of the Hospital Universitário São Francisco, Bragança Paulista. From total 348 patients with CRC monitored from 2001 to 2010, 90 were eligible for the study, with confirmed histological diagnosis of rectal adenocarcinoma, in any stage according to the TNM classification, and who had been submitted to complete resection of primary tumor. The study excluded synchronic tumors, patients with suspicion of belonging to families with hereditary CRC (familial adenomatous polyposis and non-polypoid CRC) or CRC associated with intestinal inflammatory disease and patients submitted to NCR. The study considered as rectal tumors neoplasms located below the sacral promontory, according to data collected from the surgical description. All patients were operated through laparotomy and none of them received drainage of lateral chain pelvic LNs. The mean follow-up period was 40.87 months (2-68 months). Thirty-two patients in stages III e IV received adjuvant chemotherapy, performed in six cycles, with 5-fluorouracil and leucovorin (5FU $450 \mathrm{mg} / \mathrm{m}^{2}+20 \mathrm{mg} / \mathrm{m}^{2}$ leucovorin) repeated in intervals of four to five weeks. Twenty-six patients concluded the proposed adjuvant scheme.

In the database review, the following variables were analyzed: age (over or under 65 years old), gender (male or female), ethnic group (white, black and yellow), histological degree of neoplasm (well, moderate- 
ly and poorly differentiated), type of neoplasm (mucus producer and non-producer), angiolymphatic invasion (present or absent), Dukes classifications (A, B and C) and TNM (I to IV), number of resected LNs (mean and median values), number of metastatic LNs (mean and median values), LNR (LNR-0, LNR-1 and LNR-2), follow-up period after the surgery (in months), death date and five-year survival. The OS, in months, was defined using the death date or the period between the surgery date and the last doctor's appointment.

The histological blades of each patient were hematoxylin-eosin (HE) stained, then analyzed by the Pathology Department and reviewed by an pathologist with experience in digestive tract neoplasms to confirm the histopathological diagnosis and review the considered variables. In the previous anatomopathological study, LN dissection was performed with fixed specimen. No fat clearing method was used to enhance LN recovery. Wall invasion was evaluated according to the involvement extent of mucosa, submucosa, muscularis propria, serous membrane, adipose tissue or adjacent organs. The review of neoplastic involvement of resected LNs was analyzed exclusively through the HE technique, not using the immunohistochemical method to study micrometastases.

The LNR calculation was performed using the ratio between the total number of compromised and examined LNs, categorizing the patients into three groups according to the LNR: LNR-0 for no LNs compromised by neoplasm; LNR-1: $(0.01-0.20)$ for neoplastic involvement between $1 \%$ and $20 \%$ in the studied LNs; LNR-2: (0.21-1.0) when more than 21\% of the analyzed LNs were compromised by neoplasm. The ideal cut-off for the classification of groups, considering the best specificity and sensitivity values to the selected sample, was obtained from the receiver operating characteristics (ROC) curve, in order to find the ideal LNR for the case classification.

Descriptive statistics was used to describe the clinical characteristics of the selected case and the histopathological data of neoplasm. The correlations between variables used the Pearson's test. The OS curves in a 5-year follow-up were determined using the Kaplan-Meyer method, with the Cox-Mantel test used in comparisons. The results obtained were analyzed using SPSS for Windows version 13.0, adopting the significance level of $5 \%(\mathrm{p}<0.05)$ in all tests.
Table 1. Anatomo-clinical characteristics of the studied sample.

\begin{tabular}{|c|c|}
\hline Variables & n (\%) \\
\hline \multicolumn{2}{|l|}{ Gender } \\
\hline Male & $49(54.4)$ \\
\hline Female & $41(45.56)$ \\
\hline \multicolumn{2}{|l|}{ Age } \\
\hline$<65$ years & $59(62.2)$ \\
\hline$\geq 65$ years & $34(37.8)$ \\
\hline \multicolumn{2}{|l|}{ Ethnic group } \\
\hline White & $78(86.68)$ \\
\hline Black & $8(8.88)$ \\
\hline Yellow & $4(4.44)$ \\
\hline \multicolumn{2}{|c|}{ Histological degree (differentiation) } \\
\hline Well differentiated & $23(25.55)$ \\
\hline Moderately differentiated & $63(70.0)$ \\
\hline Poorly differentiated & $4(4.44)$ \\
\hline \multicolumn{2}{|l|}{ Histological type } \\
\hline Usual & $80(88.89)$ \\
\hline Mucinous & $10(11.11)$ \\
\hline \multicolumn{2}{|l|}{ Tumor size } \\
\hline$<5 \mathrm{~cm}$ & $45(49.9)$ \\
\hline$\geq 5 \mathrm{~cm}$ & $44(49.8)$ \\
\hline \multicolumn{2}{|l|}{ Invasion of colon wall $(\mathrm{T})$} \\
\hline $\mathrm{T} 1$ & $4(4.48)$ \\
\hline $\mathrm{T} 2$ & $31(34.4)$ \\
\hline T3 & $50(55.5)$ \\
\hline $\mathrm{T} 4$ & $5(5.55)$ \\
\hline \multicolumn{2}{|l|}{ Number of committed LNs (N) } \\
\hline N0 & $61(67.77)$ \\
\hline N1 & $17(18.88)$ \\
\hline N2 & $22(24.44)$ \\
\hline \multicolumn{2}{|l|}{ Dukes classification } \\
\hline A & $15(16.67)$ \\
\hline B & $45(50.0)$ \\
\hline $\mathrm{C}$ & $30(33.33)$ \\
\hline \multicolumn{2}{|l|}{ TNM Staging (Stage) } \\
\hline I & $17(18.89)$ \\
\hline II & $41(45.56)$ \\
\hline III & $29(32.22)$ \\
\hline IV & $3(3.33)$ \\
\hline \multicolumn{2}{|l|}{ Angiolymphatic invasion } \\
\hline Present & $32(35.55)$ \\
\hline Absent & $56(62.22)$ \\
\hline \multicolumn{2}{|c|}{ Number of resected lymph nodes } \\
\hline Total & 1,226 \\
\hline Mean & 13.6 \\
\hline Median & 12 \\
\hline \multicolumn{2}{|c|}{ Metastatic lymph node ratio (LNR) } \\
\hline LNR-0 & $61(67.70)$ \\
\hline LNR-1 & $15(16.67)$ \\
\hline LNR-2 & $14(15.56)$ \\
\hline
\end{tabular}




\section{Dukes Classification}

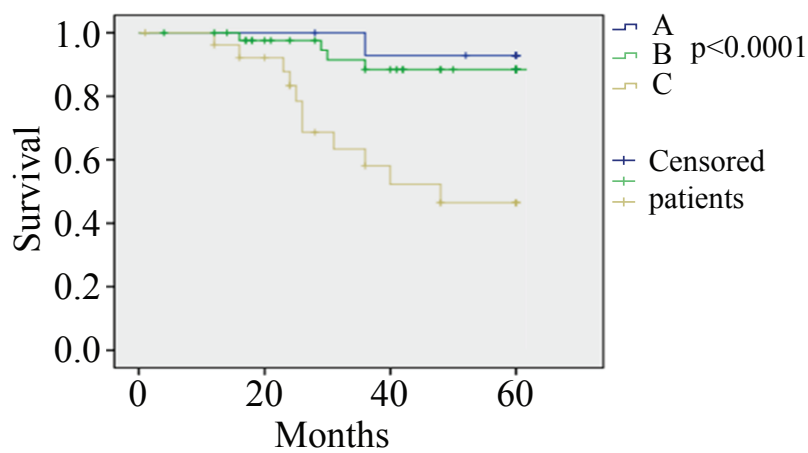

Figure 1. Five-year survival according to Dukes classification. $A=$ Stage $A ; B=$ Stage $B$ and $C=$ Stage $C$. Kaplan-Meier Curve. Cox-Mantel Test. $(p=0.0001)$.

\section{TNM (AJCC/UICC) Classification}

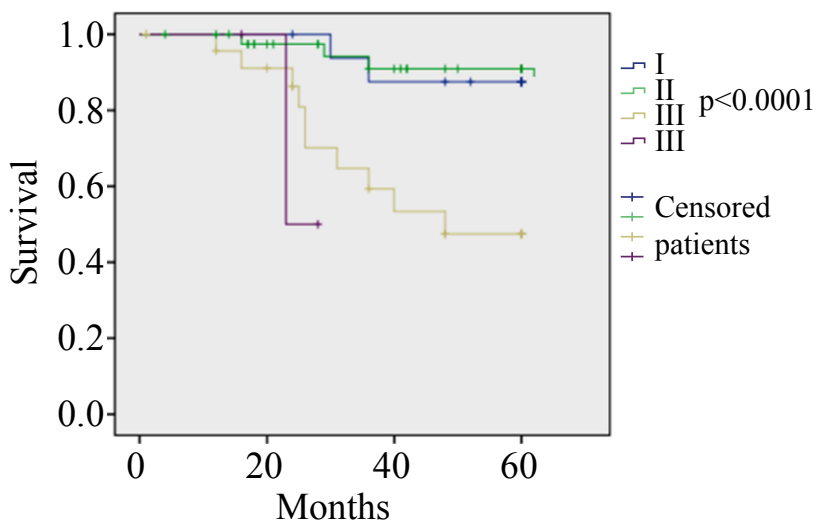

Figure 2. Five-year survival according to TNM (AJCC/UICC) classification. $I=$ Stage I; II=Stage II; III=Stage III and IV=Stage IV. Kaplan-Meier Curve. Cox-Mantel Test ( $p=0.0001)$.

\section{RESULTS}

In total, 1,226 LNs were resected, mean of 13.6 (2-40) and median of 12. In the whole analysis, 140 compromised LNs, mean of 1.55 (minimum 1 and maximum 28), were found. The mean follow-up period was 40.87 months (2-68). Table 1 shows the selected patients' clinical and histopathological characteristics.

A correlation was observed between the number of resected LNs and the number of compromised LNs $(\mathrm{p}=0.04 ; 95 \% \mathrm{CI} 0.00-0.40)$. No correlation was observed between the number of resected LNs and the
Metastatic Lymph Node Ratio (LNR)

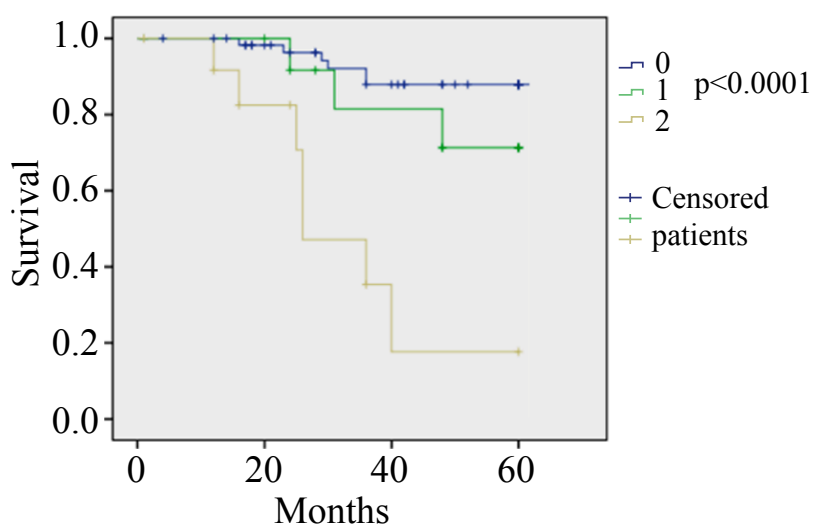

Figure 3. Five-year survival according to $L N R-0=$ no committed LNS. LNR $-1=<20 \%$ committed LNs; LNR-2= $=21 \%$ committed LNs. Kaplan-Meier Curve. Cox-Mantel Test $(p=0.0001)$.

LNR ( $\mathrm{p}=0.46$ ), but a significant correlation was observed between the number compromised LNs and the LNR ( $p=0.00001 ; 95 \%$ CI $0.50-0.75)$.

The evaluation of OS did not find any significant difference when analyzing age $(\mathrm{p}=0.08)$, gender $(p=0.06)$, histological type $(p=0.85)$, tumor size $(\mathrm{p}=0.053)$, extent of invasion in the rectal wall $(\mathrm{p}=0.06)$ and histological degree $(\mathrm{p}=0.07)$.

Fifteen patients $(16.67 \%)$ were classified as stage Ain Dukes classification, $45(50 \%)$ as B and 30 (33.3\%) as C. Figure 1 shows the OS according to Dukes classification. Worsened OS is observed in more advanced stages in Dukes classification $(\mathrm{p}=0,0001)$.

Seventeen patients $(18.8 \%)$ were classified as stage I in the TNM classification, $41(45.56 \%)$ as II, $29(32.22 \%)$ as III and $3(3.33 \%)$ as stage IV. Figure 2 shows the OS according to the TNM classification. The analysis showed that the patients in more advanced stages presented lower OS ( $\mathrm{p}=0.0001)$. Sixty-one patients $(67.77 \%)$ did not present any compromised LN (N0), while 15 (16.67\%) had less than three compromised LNs (N1) and 14 (15.56\%) more than three LNs with metastasis (N2). Eighty per cent of the patients classified as N0 survived five years, while $73 \%$ of the N1 patients no patient classified as N2 survived for a similar period. The OS was reduced when considering the number of compromised LNs $(\mathrm{p}=0.0003)$.

Sixty-one patients $(67.70 \%)$ were classified as LNR-0 for not presenting any compromised lymph 
node, $15(16.67 \%)$ as LNR-1 for having $20 \%$ or less and $14(15.56 \%)$ as LNR-2 for having more than $21 \%$ compromised LNs. Patients classified as LNR-0 presented OS greater than $85 \%$, while those classified as LNR-1 presented $73 \%$ OS and, finally, the patients with this index above $73 \%$ (LNR-2), it was less than $19 \%$. Figure 3 shows the OS when considering the LNR. The results confirm that the greater the LNR, the worse the prognosis $(p<0.0001)$.

\section{DISCUSSION}

The number of resected and examined LNs is essential for the proper staging of patients with CRC. A considerable number of LNs in the surgical specimen ensures neoplasm staging certainty and suggests the surgical resection execution according to the recommended oncologic standards, demonstrating that the extracted specimen had been submitted to a detailed histopathological analysis ${ }^{5,45,46}$. Despite all precaution of surgeons and pathologists, other variables can interfere in the number of studied LNs. Proximal colon tumors have shown to recover a significantly greater number of LNs when compared to distal colon tumors ${ }^{47}$. These numbers are even more evident when comparing the number of resected LNs in CC and $\mathrm{CRC}^{12,15,19,22,23,48}$. These differences are attributed to the possibility of resecting a greater number of lymph node chains in the proximal colon than in the distal colon and rectum ${ }^{47}$. This possibility is confirmed by the results of a study that analyzed 388 patients of CRC, showing that the mean value of recovered LNs in the right colon was higher than in the left colon (18.9 versus 12.6) ${ }^{47}$. Another study, which evaluated 2,340 patients with CRC and compared the number of recovered LNs between patients with $\mathrm{CC}$ and $\mathrm{CRC}$, showed that the mean value of recovered LNs among 1,314 patients with CRC was nine LNs, while among 1,026 patients with CC was 10 LNs, significant differences ${ }^{33}$. Our group also found similar results in a previous study, which analyzed only patients with CC and CRC located above the peritoneal reflection, with mean value of recovered LNs of 22.7(12-99). However, in this study, for which only patients with CRC were selected, the mean value was 13.6 (2-40) and median was $12 \mathrm{LN}^{4}$.

Recently, a study that dissected 12 cadavers of patients that died of diseases not related to the diges- tive system confirmed these results and demonstrated that the number of LNs in the rectum is changed depending on the site taken into account ${ }^{48}$. After removal of the entire rectum and mesorectum into a 'monobloc' before the specimens were fixed, the authors counted the number of dissected LNs in each of the nine proportional axial cuts made in the upper, middle and lower thirds. They dissected total 412 LNs, with mean $34.3 \pm 2.1$ LNs per cadaver, and confirmed that the mean number they found significantly varied with the cut height. They found on average $22.2 \mathrm{LNs}$ in cranial cuts (upper rectum), 9.8 LNs in the intermediate cuts (middle rectum) and only 2.3 in caudal cuts (lower rectum). Later, other authors, when dissecting 30 cadavers, counted the number of LNs in the mesorectum, comparing the lymph node recovery through manual dissection to the adipose tissue clearing technique. The authors also divided the mesorectum into three segments (upper, middle and lower). The mean recovered LNs per cadaver was $6.2 \pm 1.3$ (5-9); with $5.89 \pm 1.24$ recovered in the group of manual dissection and $6.60 \pm 1.29$ in the group of fat clearing, a difference that was not statistically significant. However, they point out the fact that, in the lower third of the mesorectum, the clearing technique enabled the recovery of a greater number of LNs of small sizes ${ }^{49}$. These findings are essential when the number of recovered LNs is studied in patients with CRC located below the peritoneal reflection. As this region has a lower number of LNs - exactly where the CRC is more frequent - the pathologist finds it more difficult to recover a sufficient number of LNs that enables to establish the lymph node involvement with certainty and, consequently, the patient staging. In addition, it should be emphasized that the best recommendations for the CRC treatment propose the use of NCR exactly in the patients with tumors located in the middle and lower rectum, where the number of LNs is lower.

The use of NCR reduces not only the size, but especially the quantity of recovered LNs for histological analysis. Marks et al. ${ }^{50}$, when studying specimens from 176 patients with CRC submitted to NCR, found more than 12 LNs only in $28 \%$ of the analyzed specimens and less than $6 \mathrm{LNs}$ in $32 \%{ }^{50}$. In our group, Habr-Gama et al. ${ }^{51}$ demonstrated that the number of resected LNs in CRC surgery plays an essential role in ensuring the proper staging and indicating the curative 
resection. However, they point out that these findings are not completely applicable when using NCR, at NCR, besides reducing the number of recovered LNs, creates a group of patients without LN in the surgical specimen, changing the post-chemoradiation staging. From total 281 patients submitted to NCR, 32 (11\%) did not present LNs in the surgical specimen ${ }^{51}$. They suggest that the absence of LN may reflect a better response to NCR therapy, instead of worsened surgical radicality ${ }^{51}$. With these findings, they proposed that the surgical treatment could be avoided in patients with complete clinical, endoscopic and radiological response to NCR, with the indication of a rigorous postoperative follow-up only, and the surgical therapy could be indicated to cases of unsatisfactory response or recurrence, identified through clinical, endoscopic and imaging exams during the follow-up ${ }^{52,53}$. However, there are no sufficient evidences, based on wellconducted multi-center studies, that justify the indication of non-surgical treatments to patients that present complete response after $\mathrm{NCR}^{54,55}$. All these evidences suggest that lymph node staging in patients with CRC submitted to NCR, based on the number of identified LNs only, is controversial and should be interpreted as a precaution ${ }^{54}$.

The surgical and histological technique also influences the number of recovered LNs in the surgical specimen. A study analyzing 15 patients submitted to NCR, rectal resection with total excision of mesorectum and lateral chain LN dissection, showed the recovery of $331 \mathrm{LNs}$. The study reported mean resected LNs per patient of 22.1, comprised of 258 perirectal, 73 pararectal and 27 lateral LNs. In this study, $20 \%$ of the patients showing no compromised LNs in the lateral chain at the conventional histological exam, when studied through immunohistochemistry to analyze cytokeratins (AE1/AE3), presented hidden micrometastases, and one of them had presented complete response to the tumor ${ }^{56}$.

Surgeon training is also considered an important variable for a proper lymphadenectomy. A study evaluating total 371 patients showed that the number of resected LNs significantly increases when the patients are operated by surgeons specialized in CRC treatment ${ }^{57}$. This study showed that the number of LNs removed by the trained surgeons was, on average, of $19.9 \pm 10.6$, while the number of LNs removed by non trained surgeons was $14.8 \pm 10.6$, significant differenc$\mathrm{es}^{57}$. These differences increased even more in obese patients $(\mathrm{BMI} \geq 30)$, who presented a lower number of resected LNs $(17.3 \pm 10.0$ versus $19.9 \pm 11.5)$. All these arguments suggest that, when combining the proper surgeon training, histological technique, utilization of NCR and aspects related to the patient, such as obesity and the fact of being a male, the number of identified LNs in the CRC specimens can be lower, further aggravating the correct prognostic classification ${ }^{18,20}$.

Perhaps, the most important objective of a proper lymphadenectomy in patients with CRC is to select, with superior accuracy, those who will benefit from a complementary adjuvant treatment ${ }^{43}$. When comparing the OS of patients with $\mathrm{CRC}$ in relation to the number of extirpated LNs, it is observed that the improper resection significantly worsens the disease prognosis ${ }^{16,58}$. The ideal number of LN to be resected in the CRC is still a reason for controversies ${ }^{4,12,36}$. Most authors consider the range of 10 and 17 LNs as ideal ${ }^{12,36,59,60}$. In the USA, the National Quality Forum and other organizations have recently defined that, in patients with CRC, the minimum number of 12 LNs should be resected, in this parameter, which is one of the most important in the quality analysis of a unit specialized in the disease treatment ${ }^{61}$. Then, resections with less than 12 LNs can be considered improper, not enabling the correct staging. Many pathologists prefer to classify patients with less than 12 LNs identified in the surgical specimen as NX or add a note to the anatomopathological study report emphasizing the risk of predicting the lymph node status based on the number of dissected $\mathrm{LNs}^{4,37}$. Resections with insufficient number of LNs contribute to the phenomenon of stage migration described by Feinstein et al. in $1985^{30}$, known as Will Rogers phenomenon. In fact, it is a frequent phenomenon in oncology, which occurs when the prediction of favorable survival is threatened by unfavorable progress ${ }^{4,30}$. The phenomenon is even more frequent in cases of CRC, in which, after NCR, the number of recovered LNs is usually still low.

In order to improve the lymph node staging and reduce the possibility of stage migration, the incorporation or new strategies has been studied. Investigations have evaluated the importance of LNR as a variable related to $\mathrm{OS}$ in patients with $\mathrm{CRC}^{4,5,24,31-41}$. Berger et al. ${ }^{31}$ evaluated the OS and DFS in patients 
with CC classified as stages II and III and submitted to adjuvant chemotherapy. They selected patients who presented the mean number of $13 \mathrm{LNs}$ analyzed. From total 3,411 patients, 648 (19\%) did not have lymph node metastases, 1,857 (54\%) had up to three compromised LNs and 906 (27\%) had more than three metastatic LNs. When they classified the same patients into groups according to the LNR ( $\mathrm{LNR}<0.05 ; 0.05-0.19$; $0.2-0.39$ and $0.4-1.0$ ), they observed that the LNR was related to the OS and DFS in patients with 10 to 15 or more than 15 resected LNs, but not in those with less than 10 LNs in the surgical specimen ${ }^{31}$. Unlike this study, De Ridder et al. ${ }^{40}$, when comparing the TNM classification to a system that included the LNR, in a group of patients that presented mean $10 \mathrm{LNs}$, observed that the capability to establish with higher precision the prognostic stages using the LNR was 31 versus $25 \%$ only with the TNM classification. They concluded that the LNR is a variable that can improve staging in improper lymph node resection.

A multi-center study published by Wang et al. ${ }^{33}$ that evaluated 24,477 patients with $\mathrm{CC}$ in stage III according to the TNM classification, observed that it was possible to recover more than $15 \mathrm{LNs}$ in the surgical specimen in 7,469 (30.5\%) of them. They categorized the patients into four groups according to the LNR (no involvement, 1/14, 1/4 and 1/2, respectively). They observed that the OS for patients in stages IIIA, IIIB and IIIC was $71.3,51.7$ and $34.0 \%$, respectively. No significant differences were found in OS, according to the LNR, in the patients classified as stage IIIA. In the patients classified as stage IIIB, the OS according to the four classification classes (LNR-1 to LNR-4) was 63.5, 54.7, 44.4 and $34.2 \%$, respectively, confirming that the higher the LNR, the worse the OS. In patients classified as stage IIIC, the OS according to LNR-2, LNR-3 and LNR-4 was $49.6,41.7$, and $25.2 \%$, respectively, confirming that the LNR was also a variable related to OS and DFS. Curiously, Derwinger et al. ${ }^{62}$ observed that the LNR could also be considered a prognosis factor in 136 patients with CRC classified as stage IV according to the TNM system. They categorized the patients into three groups: $\mathrm{LNR}=0-0.15, \mathrm{LNR}=0.16-0.65$ and $\mathrm{LNR}=0.66-1$. Through a univariate analysis, they reported that the LNR showed to be a more important prognostic factor to predict the OS and indication of adjuvant chemotherapy than the number of compromised LNs. Rosenberg et al. ${ }^{35}$ studied the importance of LNR in 3,026 patients, $1,763(58.2 \%)$ with CC and $1,263(41.8 \%)$ with CRC. The rate of potentially curative surgeries was $77.4 \%$ and the mean proportions of resected and metastatic LNs to each patient were 18.3 and 2.6, respectively. After the statistic study, they established that the best cohort level for the LNR classification was $0.17,0.41$ and 0.69 . They observed that the OS of patients without compromised LNs was $87 \%$, while in patients with compromised LNs, it was $60.3,34.4$ and $17.6 \%$, increasing around $5 \%$ when the LNR classification was adopted. When considering all patients as a single group, they observed that the LNR presented a greater prognostic power than the number of compromised LNs. When they categorized the patients into two groups - with CC and with CRC -, they observed that the LNR remained as an independent prognostic variable to both groups ${ }^{35}$. A series of studies performed later evaluated the importance of LNR in CRC $\mathrm{C}^{4,38,39,43,63-65}$. In all of them, the LNR was considered an independent variable for OS and DFS of patients with CRC, especially in patients of stages II and III in the TNM classification.

In Brazil, to our knowledge, only two studies have evaluated the importance of LNR in patients with $\mathrm{CRC}^{36,37}$. In the first, the authors analyzed 106 patients, most were males $(53.8 \%)$. The median value of dissected LNs per patient was 11.5 (3-45) and only $58.5 \%$ of the patients had more than 10 dissected LNs. The mean follow-up period was $25.05 \pm 15.21$ months (2-64 months), and $32.1 \%$ of patients died of the disease. The univariate analysis showed that the OS of patients included in the study was related to LNR, disease staging and tumor recurrence. However, in the multivariate analysis, they observed that the only independent factor related to OS was TNM. Perhaps, these findings are related to the fact that more than half the selected patients in the study $(58.1 \%)$ belonged to stage IV according to the TNM classification - patients known to have the worst prognosis - and that the number of LNs considered for the multivariate analysis was 10 and, even so, in a small number of patients $^{36}$. The authors justify that the possible explanations for the fact that the LNR does not predict OS were: sample heterogeneity in relation to the initial tumor staging, number of dissected LN, short follow-up 
period, small sample and non evaluation of presence of serious comorbidities and postoperative complications $^{36}$. In the second study published in Brazil, the authors studied 113 patients with $\mathrm{CC}$ and upper $\mathrm{CRC}^{37}$. They excluded patients with middle and lower CRC, as they had been submitted to NCR, and patients with less than 12 LNs in the surgical specimen. They categorized the patients according to the LNR into three groups: LNR-0, with patients without lymph node involvement; LNR-1: involvement of max. $20 \%$ of examined LN; and LNR-2: with neoplastic involvement in $21 \%$ or more of examined LNs. They found a significant difference in OS when analyzing that in the patients belonging to LNR-0, the OS was above $80 \%$, while in patients classified as LNR-1 and LNR-2 the OS was under $60 \%$ and $40 \%$, respectively. With the multivariate analysis, they reported that the LNR can be considered an independent prognostic variable.

The results of all these studies were confirmed by a recently-published systematic literature review that selected total 16 studies with good level of evidence. The authors included 33,984 patients with CC or CRC classified as stage III. The results showed that the capability to predict OS as provided by the LNR was greater than that found only through the number of committed $\mathrm{LNs}^{66}$. They found the relative risk for OS of 2.36 (95\%CI 2.14-2.61) and for DFS of 3.71 (95\%CI 2.56-5.38).

However, most studies that have evaluated the LNR as a possible variable related to OS studied patients with $\mathrm{CC}^{31-34,38-41}$ or with $\mathrm{CC}$ and $\mathrm{CRC}$ as a single group ${ }^{4,5,24,35-38,62,63}$. Few studies have evaluated whether the LNR could be related to OS in patients exclusively with CRC, and even so, these studies do not clearly state whether the patients were categorized according to the criterion of having been submitted to NCR or not, which could influence the LNR calculation ${ }^{42,44,64-66}$. Peng et $\mathrm{al}^{42}$ studied, for the first time in the literature, the relation between LNR and OS in 318 patients with CRC previously submitted to curative-intention resection. With mean follow-up of 41 months and mean number of 12 resected LNs, they observed that OS and DFS were 58.82 and $59.8 \%$, respectively. The multivariate analysis showed that, when considered as a continuous variable, LNR was the most important prognostic factor in OS. When they categorized the patients into three groups $(\mathrm{LNR}<0.4$, between $0.14-0.40$ and between $0.5-1$ ), they observed that the OS was $72.19,61.92$ and $38.47 \%$, respectively, statistically significant differences. They concluded that the LNR can also be considered an important prognostic factor in patients with $\mathrm{CRC}$ who presented positive $\mathrm{LNs}^{43}$. In the same year, Peschaud et al. ${ }^{44}$ also evaluated the prognostic power of LNR in patients with CRC. They analyzed OS, DFS and LNR in 307 patients with CRC and examined the mean number of 22 LNs. From the 307 patients, $178(57.9 \%)$ did not show lymph node involvement, $67(21.8 \%)$ had up to three committed LNs and 62 had more than three metastatic LNs. When they categorized the patients into four groups, according to: $\mathrm{LNR}=0$ (no involvement), $\mathrm{LNR}=0.01$ to 0.07 , $\mathrm{LNR}>0.07$ to 0.2 and LNR $>0.2$, they observed that the LNR was a variable related to OS, not the number of committed LNs. When they individually analyzed the patients with less than 12 examined $12 \mathrm{LNs}$, even so, the LNR was related to OS and DFS. They concluded that the LNR is the variable with the greatest prognostic power of both OS and DFS in patients with CRC, even in those whose surgical specimen presents less than 12 studied LNs.

Recently, Kang et al. ${ }^{67}$, in an attempt to evaluate the importance of LNR in patients with CRC and positive LNs, even after they had been submitted to NCR (positive ypNs), studied total 75 patients, categorizing them into two groups, based on median LNR (0.143). They observed that the abdominoperineal resection of the rectum, the involvement of circumferential margins and LNR $>0.143$ were variables related to reduced OS. They concluded that the LNR is an independent prognostic variable in patients with CRC submitted to NCR, allowing also a better categorization than ypN staging. They propose that the LNR should be considered an additional prognostic factor in patients with CRC after NCR. Another study with a similar objective, when evaluating 281 patients with CRC submitted to NCR associated with total resection of the mesorectum, categorized the patients according to LNR into: small $(0-0.09)$, moderate $(0.09-0.36)$ and high $(\geq 0.36)^{68}$. They observed that the patients with CRC previously submitted to NCR frequently present less than 12 dissected LNs, despite the intense surgical rigor and careful pathological analysis. They concluded that, in patients with CRC with less than 12 studied LNs, 
the LNR is a better prognostic factor for OS than the number of recovered or metastatic LNs.

A study conducted by the Japanese Society of Colorectal Cancer (JSCRC) to define the impact of LNR on patients with lower CRC in stage III, analyzed 501 patients submitted to curative resection with total excision of the mesorectum, coming from 12 institutions, and categorized them into four groups according to the $\mathrm{LNR}^{69}$. From total 501 patients, 381 were submitted to dissection of LNs from the lateral pelvic wall. The mean number of resected LNs in patients submitted or not to lateral dissection was 45 and 17 , respectively. The study excluded 45 patients who had less than 12 LNs in the surgical specimen. Among the several clinical and pathological parameters analyzed, they observed that the number of committed LNs and LNR were variables related to the disease prognosis. When they added LNR to the seventh edition of TNM classification as a covariable, they observed that the new staging system and LNR were independent prognostic variables in patients with CRC in stage III. The Japanese Society proposes to add the LNR concept to the staging system of AJCC to improve the accuracy of LN status in patients with lower CRC. This idea is defended by others who believe that the LNR can become a better method to select patients with CRC eligible to adjuvant therapy ${ }^{43,70,71}$. Recently, investigators observed that the LNR is a variable that predicts the development of pulmonary metastases in patients with $\mathrm{CRC}^{72}$.

To our knowledge, in Brazil, the relation between LNR and OS in patients with CRC submitted or not to NCR protocols has not been evaluated. In this study, the authors decided to study the impact of LNR and other variables on OS exclusively in patients with CRC. The study selected only patients that had been submitted to surgical resection, regardless of the number of recovered LNs in the surgical specimen, and that had not received NCR. The study excluded patients submitted to NCR to prevent the LNR-based categorization from having interferences related to the reduction of total and committed LNs due to NCR. The main purpose was to observe whether the systematic surgery alone for $\mathrm{CRC}$, with total excision of the mesorectum, and performed by a trained medical team for the disease treatment, could confirm the relation between LNR and OS. The review of histopathologi- cal reports showing no involvement of proximal, distal and circumferential margins in all selected specimens, and the mean number of 13.6 resected LNs, with median of $12 \mathrm{LNs}$ combined with similar OS to other studied centers, allows to conclude that the patients were submitted to surgical resection following the best oncologic principles.

In this study, when analyzing the clinical variables, age, gender and ethnic group in relation to OS, no significant differences were observed. When the histological type of the tumor is considered, previous studies demonstrated that mucus-secreting tumors or with signet-ring cells present lower OS, although accounting for $15 \%$ of the CRC cases $^{73,74}$. They also demonstrated that the mean survival of these patients is 45.4 months, compared to 78.5 months in patients with tumors of tubular pattern $^{73}$. In this study, no relation was found between the histological type of the tumor and OS. This finding is probably related to the small number $(8.98 \%)$ of mucus-secreting tumors in the studied cases. Perhaps this small number is due to the fact that only patients with CRC were selected, and in these patients, the proportion of this histological type is smaller when compared to CC patients, and due to the fact that the study excluded patients with suspicion of belonging to families with HNPCC, which present higher incidence of mucus-secreting tumors ${ }^{75}$. Although tumors with worse histological degree are also associated to worse OS, this study did not observe any relation between worse histological degree and smaller OS. Perhaps the small number of little differentiated tumors found in the study (4.4\%), just as it happened when considering the histological type, influenced the result.

Regarding the tumor size, the study observed that tumor of more than five centimeters presented marginal significance in relation to OS $(\mathrm{p}=0.053)$, while the extent of colon wall invasion had no relation with worsened prognosis. Regarding the tumor size, the results obtained agree with those found in the literature. Larger tumors usually present small chances of curative resection (R0), greater possibility of invasion of adjacent structures (prostate, bladder, vagina, presacral fascia), locoregional recurrence and distant metastases, factors that influence the OS. When considering the extent of rectal wall penetration as a variable 
related to OS, no relation with OS was found. Perhaps the high concentration of tumors TII and TIII, 89.94\% of the studied cases, may have influenced the result.

The Dukes classification, the TNM system, the number of committed LNs and the LNR were variables related to OS. The study observed that the patients classified as LNR-0 presented SG above $85 \%$, while the patients classified as LNR-1 presented $73 \%$, and those classified as LNR-3 presented OS below $19 \%$. The results of this study showed that the greater the LNR, the worse the OS of patients with CRC, even in those not submitted to NRC. The study confirmed that the LNR has greater predictive power of OS than the number of committed LNs identified in the surgical specimen and that it is similar to Dukes staging and LNR systems. It should be noted that the LNR could predict the OS even in patients with less than 12 recovered LNs (results not shown) and who would be properly categorized according to the best current directions for CRC staging.

Although the study evaluated only patients with CRC not submitted to NRC, the results obtained confirmed the impact of LNR on OS of patients with CRC. However, some considering should be pointed out. Most authors that have evaluated the prognostic impact of LNR on OS have analyzed a small number of cases, patients with differences regarding their biotype, gender, tumors in different locations of the rectum, of distinct histological types and degrees, operated by surgeons with different levels of experience and, mainly, patients submitted to distinct protocols of adjuvant or neoadjuvant treatment. Another factor of crucial importance is the absence of standardization at the cohort levels used to categorize the patients into groups according to the LNR in different studies. Only with the results of systematic reviews of multi-center, prospective studies, with an expressive number of cases, better standardization of inclusion criteria and that use standardized cohort levels it will be possible to definitively confirm the prognostic impact of LNR and propose its inclusion as a useful variable to improve the staging systems currently available. Until then, due to the easy-to-use calculation of no additional cost, the routine use of LNR is recommended as a valid instrument to help the correct categorization of patients with CRC, reducing staging errors.

\section{CONCLUSION}

In the circumstances of this study, the results obtained allow to confirm the impact of LNR on the fiveyear survival of patients with CRC not submitted to preoperative chemoradiation treatment.

RESUMO: Metástases linfonodais representam um dos principais fatores prognósticos no câncer colorretal. A ressecção linfonodal inadequada relaciona-se à menor sobrevida. A proporção entre linfonodos metastáticos (PLM) vem sendo utilizada como fator prognóstico em doentes com câncer de cólon. Poucos estudos avaliaram o impacto da PLM na sobrevida de doentes com câncer retal. Objetivo: Avaliar o impacto da PLM na sobrevida de doentes com câncer de reto não submetidos à quimioradioterapia préoperatória. Métodos: Foram incluídos 90 doentes com adenocarcinoma retal excluindo-se tumores de cólon, tumores sincrônicos, câncer colorretal hereditário e aqueles submetidos a tratamento radioquimioterápico pré-operatório. Os doentes foram divididos em três grupos segundo a PLM: PLM-0, sem linfonodos comprometidos; PLM-1, 1 a 20\% dos linfonodos comprometidos; e PLM-2, mais de $21 \%$ dos linfonodos comprometidos. A identificação do ponto de corte da amostra selecionada foi obtida a partir da curva de características de operação do receptor (curva ROC). A sobrevida foi avaliada pelo teste de Kaplan-Meier, a diferença entre os grupos pelo teste de Cox-Mantel e a correlação entre as variáveis pelo teste de Pearson, adotando-se um nível de significância de 5\% $(\mathrm{p} \leq \mathbf{0 , 0 5})$. Resultados: A sobrevida em cinco anos relacionou-se à classificação de Dukes, TNM, número de linfonodos metastáticos e PLM. Houve diferença na sobrevida ao compararem-se as diferentes classes de PLM. Doentes classificados como PLM-0 apresentaram sobrevida de 85\%, enquanto os pertencentes às classes PLM-1 e PLM-2, de 73 e $19 \%$, respectivamente $(p=0,0001)$. Conclusão: Os resultados encontrados mostraram que a PLM tem impacto na sobrevida de doentes com câncer de reto não submetidos à neoadjuvância.

Palavras-chave: reto; neoplasias colorretais; linfonodos; excisão de linfonodo; análise de sobrevida. 


\section{REFERENCES}

1. Centers for Disease Control and Prevention (CDC). Vital signs: colorectal cancer screening, incidence, and mortality - United States, 2002-2010. MMWR Morb Mortal Wkly Rep 2011;60(26):884-9.

2. Coleman MP, Quaresma M, Berrino F, Lutz JM, De Angelis $\mathrm{R}$, Capocaccia $\mathrm{R}$, et al. Cancer survival in five continents: a worldwide population-based study (CONCORD). Lancet Oncol 2008;9(8):730-56.

3. Boyle P, Ferlay J. Cancer incidence and mortality in Europe, 2004. Ann Oncol 2005;16(3):481-8.

4. Priolli DG, Cardinalli IA, Pereira JA, Alfredo CH, Margarido NF, Martinez CA. Metastatic lymph node ratio as an independent prognostic variable in colorectal cancer: study of 113 patients. Tech Coloproctol 2009;13(2):113-21.

5. Noura S, Ohue M, Kano S, Shingai T, Yamada T, Miyashiro I, et al. Impact of metastatic lymph node ratio in node-positive colorectal cancer. World J Gastrointest Surg 2010;2(3):70-7.

6. Adjuvant therapy of colon cancer--results of a prospectively randomized trial. Gastrointestinal Tumor Study Group. N Engl J Med 1984;310(12):737-43.

7. Sobin LH, Wittekind C. TNM classification of malignant tumors. 6th ed. New York: Wiley-Liss; 2002.

8. Dukes CE. The classification of cancer of the rectum. J Pathol 1932;35:323-32.

9. Astler VB, Coller FA. The prognostic significance of direct extension of carcinoma of the colon and rectum. Ann Surg 1954;139(6):846-52.

10. Nelson H, Petrelli N, Carlin A, Couture J, Fleshman J, Guillem J, et al. Guidelines 2000 for colon and rectal cancer surgery. J Natl Cancer Inst 2001;93(8):583-96.

11. Benson AB 3rd. New approaches to the adjuvant therapy of colon cancer. Oncologist 2006;11(9):973-80.

12. Wong JH, Severino R, Honnebier MB, Tom P, Namiki TS. Number of nodes examined and staging accuracy in colorectal carcinoma. J Clin Oncol 1999;17(9):2896-900.

13. Swanson RS, Copton CC, Stewart AK, Bland KI. The prognosis of T3N0 colon cancer is dependent of the number of nodes retrieved on resection. Ann Surg Oncol 2003; 10:65-71.

14. Compton CC, Fielding LP, Burgart LJ, Conley B, Cooper HS, Hamilton SR, et al. Prognostic factors in colorectal cancer. College of American Pathologists Consensus Statement 1999. Arch Pathol Lab Med 2000;124(7):979-94.

15. Cianchi F, Palomba A, Boddi V, Messerini L, Pucciani F, Perigli G, et al. Lymph node recovery from colorectal tumor specimens: recommendation for a minimum number of lymph nodes to be examined. World J.Surg 2002;26(3):384-9.

16. LeVoyer TE, Sigurdson ER, Hanlon AR, Mayer RJ, MacDonald JS, Catalano PJ, et al. Colon cancer survival is associated with increasing number of lymph nodes analyzed: a secondary survey of intergroup trial INT-0089. J Clin Oncol 2003;21(15):2912-9.
17. Bilimoria KY, Palis B, Stewart AK, Bentrem DJ, Freel $\mathrm{AC}$, Sigurdson ER, et al. Impact of tumor location on nodal evaluation for colon cancer. Dis Colon Rectum 2008;51(2):154-61.

18. Latkauskas T, Lizdenis P, Janciauskiene R, Pranys D, Tamelis A, Pavalkis D. Lymph node retrieval after resection of rectal cancer following preoperative chemoradiotherapy. Medicina (Kaunas) 2010;46(5):299-304.

19. Elferink MA, Siesling S, Lemmens VE, Visser O, Rutten HJ, van Krieken $\mathrm{JH}$, et al. Variation in lymph node evaluation in rectal cancer: a Dutch nationwide population-based study. Ann Surg Oncol 2011;18(2):386-95.

20. Wichmann MW, Müller C, Meyer G, Strauss T, Hornung HM, Lau-Werner U, et al. Effect of preoperative radiochemotherapy on lymph node retrieval after resection of rectal cancer. Arch Surg 2002;137(2):206-10.

21. Ha YH, Jeong SY, Lim SB, Choi HS, Hong YS, Chang HJ, et al. Influence of preoperative chemoradiotherapy on the number of lymph nodes retrieved in rectal cancer. Ann Surg 2010;252(2):336-40.

22. Norwood MG, Sutton AJ, West K, Sharpe DP, Hemingway D, Kelly MJ. Lymph node retrieval in colorectal cancer resection specimens: national standards are achievable, and low numbers are associated with reduced survival. Colorectal Dis 2010;12(4):304-9.

23. Murphy J, Pocard M, Jass JR, O'Sullivan GC, Lee G, Talbot IC. Number and size of lymph nodes recovered from dukes B rectal cancers: correlation with prognosis and histologic antitumor immune response. Dis Colon Rectum 2007;50(1):1526-34.

24. Tong LL, Gao P, Wang ZN, Song YX, Xu YY, Sun Z, et al. Can lymph node ratio take the place of $\mathrm{pN}$ categories in the UICC/AJCC TNM classification system for colorectal cancer? Ann Surg Oncol 2011;18(9):2453-60.

25. Celen O, Yildirim E, Berberoglu U. Prognostic impact of positive lymph node ratio in gastric carcinoma. J Surg Oncol 2007;96(2):95-101.

26. Persiani R, Rausei S, Biondi A, Boccia S, Cananzi F, D’Ugo D. Ratio of metastatic lymph nodes: impact on staging and survival of gastric cancer. Eur J Surg Oncol 2008;34(5):519-24.

27. Herr HW. Superiority of ratio based lymph node staging for bladder cancer. J Urol 2003;169(3):943-5.

28. Schiffman SC, McMasters KM, Scoggins CR, Martin RC, Chagpar AB. Lymph node ratio: a proposed refinement of current axillary staging in breast cancer patients. J Am Coll Surg 2011;213(1):45-52.

29. Bhatti I, Peacock O, Awan AK, Semeraro D, Larvin M, Hall RI. Lymph node ratio versus number of affected lymph nodes as predictors of survival for resected pancreatic adenocarcinoma. World J Surg 2010;34(4):768-75.

30. Feinstein AR, Sosin DM, Wells CK. The Will Rogers phenomenon: Stage migration and new diagnostic techniques as a source of misleading statistics for survival in cancer. $\mathrm{N}$ Engl J Med 1985;312(25):1604-8. 
31. Berger AC, Sigurdson ER, Le Voyer T, Hanlon A, Mayer RJ, Macdonald JS, et al. Colon cancer survival is associated with decreasing ratio of metastatic to examined lymph nodes. $\mathrm{J}$ Clin Oncol 2005;23(34):8706-12.

32. Lee HY, Choi HJ, Park KJ, Shin JS, Kwon HC, Roh MS, et al. Prognostic significance of metastatic lymph node ratio in node-positive colon carcinoma. Ann Surg Oncol 2007;14(5):1712-7.

33. Wang J, Hasset JM, Dayton MT, Kulaylat MN. Lymph node ratio: role in the staging of node-positive colon cancer. Ann Surg Oncol 2008;15(6):1600-8.

34. Derwinger K, Carlsson G, Gustavsson B. A study of lymph node ratio as a prognostic marker in colon cancer. Eur J Surg Oncol 2007;34(7):771-5.

35. Rosenberg R, Friederichs J, Schuster T, Gertler R, Maak M, Becker K, et al. Prognosis of patients with colorectal cancer is associated with lymph node ratio: a single-center analysis of 3,026 patients over a 25-year time period. Ann Surg 2008;248(6):968-78.

36. Trufelli DC, Miranda VC, Palos CC, Ramos E, Abrão MN, Silva VA, et al. Positive/total dissected lymph nodes ratio as a prognostic factor in colorectal cancer. Rev Ass Med Bras 2007;53(6):539-42.

37. Priolli DG, Cardinalli IA, Alfredo $\mathrm{CH}$, Spadari APP, Máximo FR, Margarido NF, et al. Proporção de linfonodos metastáticos como variável independente de prognóstico no câncer colorretal. J Coloproctol 2008;28(4):431-42.

38. Park IJ, Choi GS, Jun SH. Nodal stage of stage III colon cancer: the impact of metastatic lymph node ratio. J Surg Oncol 2009;100(3):24-3.

39. Chin CC, Wang JY, Yeh CY, Kuo YH, Huang WS, Yeh CH. Metastatic lymph node ratio is a more precise predictor of prognosis than number of lymph nodes metastases in stage III colon cancer. Int J Colorectal Dis 2009;24(11):1297-302.

40. De Ridder M, Vinh-Hung V, Van Nieuwenhove Y, Hoorens A, Sermeus A, Storme G. Prognostic value of lymph node ratio in node positive colon cancer. Gut 2006;55(11):1681.

41. Schumacher P, Dineen S, Barnett C Jr, Fleming J, Anthony $\mathrm{T}$. The metastatic lymph node ratio predicts survival in colon cancer. Am J Sur 2007;194(6):827-31.

42. Peng J, Xu Y, Guan Z, Zhu J, Wang M, Cai G, et al. Prognostic significance of the metastatic lymph node ratio in node-positive rectal cancer. Ann Surg Oncol 2008;15(11):3118-23.

43. Kim YS, Kim JH, Yoon SM, Choi EK, Ahn SD, Lee SW, et al. Lymph node ratio as a prognostic factor in patients with stage III rectal cancer treated with total mesorectal excision followed by chemoradiotherapy. Int J Radiat Oncol Biol Phys 2009;74(3):796-802.

44. Peschaud F, Benoist S, Julié C, Beauchet A, Penna C, Rougier $\mathrm{P}$, et al. The ratio of metastatic to examined lymph nodes is a powerful independent prognostic factor in rectal cancer. Ann Surg 2008;248(6):1067-73.

45. Mönig SP, Baldus SE, Zirbes TK, Schröder W, Lindemann DG, Dienes HP, et al. Lymph node size and metastatic infiltration in colon cancer. Ann Surg Oncol 1999;6(6): 579-81.

46. Wood TF, Saha S, Morton DL, Tsioulias GJ, Rangel D, Hutchinson $\mathrm{W} \mathrm{Jr}$, et al. Validation of lymphatic mapping in colorectal cancer: In vivo, ex vivo, and laparoscopic techniques. Ann Surg Oncol 2001;8(2):150-7.

47. Pappas AV, Lagoudianakis EE, Dallianoudis IG, Kotzadimitriou KT, Koronakis NE, Chrysikos ID, et al. Differences in colorectal cancer patterns between right and left sided colorectal cancer lesions. J BUON 2010;15(3): 509-13.

48. Miscusi G, di Gioia CR, Patrizi G, Gravetz A, Redler A, Petrozza V. Anatomical lymph node mapping in normal mesorectal adipose tissue. Dis Colon Rectum 2010;53(12):1640-4.

49. Thakur S, Somashekar U, Shiv Kumar Chandrakar, Sharma D. Anatomic study of distribution, numbers, and size of lymph nodes in mesorectum in indians: a autopsy study. Int J Surg Pathol 2011;19(3):315-20.

50. Marks JH, Valsdottir EB, Rather AA, Nweze IC, Newman DA, Chernick MR. Fewer than 12 lymph nodes can be expected in a surgical specimen after high-dose chemoradiation therapy for rectal cancer. Dis Colon Rectum 2010;53(7):1023-9.

51. Habr-Gama A, Perez RO, Proscurshim I, Rawet V, Pereira $\mathrm{DD}$, Sousa AH, et al. Absence of lymph nodes in the resected specimen after radical surgery for distal rectal cancer and neoadjuvant chemoradiation therapy: what does it mean? Dis Colon Rectum 2008;51(3):277-83.

52. Habr-Gama A, Perez RO, Wynn G, Marks J, Kessler H, Gama-Rodrigues J. Complete clinical response after neoadjuvant chemoradiation therapy for distal rectal cancer: characterization of clinical and endoscopic findings for standardization. Dis Colon Rectum 2010;53(12):1692-8.

53. Habr-Gama A, Perez RO, São Julião GP, Proscurshim I, Gama-Rodrigues J. Nonoperative approaches to rectal cancer: a critical evaluation. Semin Radiat Oncol 2011;21(3):234-9.

54. Singh-Ranger G, Kumar D. Current concepts in the nonoperative management of rectal cancer after neoadjuvant chemoradiation. Anticancer Res 2011;31(5):1795-800.

55. Baxter NN, Morris AM, Rothenberger DA, Tepper AJ. Impact of preoperative radiation for rectal cancer on subsequent lymph node evaluation: a population-based analysis. Int J Radiat Oncol Biol Phys 2005;61(2):426-31.

56. Coy CS, Meirelles LR, Leal RF, Ayrizono ML, Góes JR, Fagundes JJ. Evaluation of lateral lymph node metastases in advanced distal rectal cancer. Hepatogastroenterology 2010;57(104):1363-6.

57. Barbas A, Turley R, Mantyh C, Migaly J.Advanced fellowship training is associated with improved lymph node retrieval in colon cancer resections. J Surg Res 2011;170(1):e41-6.

58. Sigurdson ER. Lymph node dissection: Is it diagnostic or therapeutic? J Clin Oncol 2003;21(6):965-7.

59. Goldstein NS, Sanford W, Coffey M, Layfield LJ. Lymph node recovery from colorectal resection specimens removed 
for adenocarcinoma: Trends over time and a recommendation for a minimum number of lymph nodes to be recovered. Am J Clin Pathol 1996;106(2):209-16.

60. Chen SL, Bilchik AJ. More extensive nodal dissection improves survival for stages I to III of colon cancer: a population-based study. Ann Surg 2006;244(4):602-10.

61. Wong SL, Ji H, Hollenbeck BR, Morris AM, Baser O, Birkmeyer JD. Hospital lymph node examination rates and survival after resection for colon cancer. JAMA 2007;298(18):2149-54.

62. Derwinger K, Gustavsson B. A study of lymph node ratio in stage IV colorectal cancer. World J Surg Oncol 2008;6:127.

63. Vather R, Sammour T, Kahokehr A, Connolly AB, Hill AG. Lymph node evaluation and long-term survival in stage II and Stage III colon cancer: a national study. Ann Surg Oncol 2009;16(3):585-93.

64. Moug SJ, Saldanha JD, McGregor JR, Balsitis M, Diament RH. Positive lymph node retrievel ratio optimises patient staging in colorectal cancer. Br J Cancer 2009;100(10): 1530-3.

65. Vaccaro CA, Im V, Rossi GL, Quintana GO, Benatti ML, Perez de Arenaza D, et al. Lymph node ratio as prognostic factor for colon cancer treated by colorectal surgeons. Dis Colon Rectum 2009;52(7):1244-50.

66. Ceelen W, Van Nieuwenhove Y, Pattyn P. Prognostic value of the lymph node ratio in stage III colorectal cancer: a systematic review. Ann Surg Oncol 2010;17(11):2847-55.

67. Kang J, Hur H, Min BS, Lee KY, Kim NK. Prognostic impact of the Lymph node ratio in rectal cancer patients who underwent preoperative chemoradiation. J Surg Oncol 2011;104(1):53-8

68. Klos CL, Bordeianou LG, Sylla P, Chang Y, Berger DL. The prognostic value of lymph node ratio after neoadjuvant chemoradiation and rectal cancer surgery. Dis Colon Rectum 2011;54(2):171-5.
69. Kobayashi H, Mochizuki H, Kato T, Mori T, Kameoka S, Shirouzu K, et al. Study Group for Rectal Cancer Surgery of the Japanese Society for Cancer of the Colon and Rectum. Lymph node ratio is a powerful prognostic index in patients with stage III distal rectal cancer: a Japanese multicenter study. Int J Colorectal Dis 2011;26(7):891-6.

70. Yalman D, Demirci S, Bolukbasi Y, Caliskan C, Ozkok S. Postoperative radiotherapy in rectal cancer: long-term results of 290 patients. Hepatogastroenterology 2010;57(102-103): 1099-105.

71. Dekker JW, Peeters KC, Putter H, Vahrmeijer AL, van de Velde CJ. Metastatic lymph node ratio in stage III rectal cancer; prognostic significance in addition to the 7 th edition of the TNM classification. Eur J Surg Oncol 2010;36(12):1180-6.

72. Watanabe K, Saito N, Sugito M, Ito M, Kobayashi A, Nishizawa Y. Predictive factors for pulmonary metastases after curative resection of rectal cancer without preoperative chemoradiotherapy. Dis Colon Rectum 2011;54(8):989-98.

73. Nissan A, Guillem JG, Paty PB, Wong WD, Cohen AM. Signet-ring cell carcinoma of the colon and rectum: a matched control study. Dis Colon Rectum 1999;42(9):1176-80.

74. Börger ME, Gosens MJ, Jeuken JW, van Kempen LC, van de Velde CJ, van Krieken JH, et al. Signet ring cell differentiation in mucinous colorectal carcinoma. J Pathol 2007;212(3):278-86.

75. Martinez CAR, Priolli DG, Cardinalli IA, Pereira JA, Portes $\mathrm{AV}$, Margarido NF. Influência da localização do tumor na expressão tecidual da proteína p53 em doentes com câncer colorretal: estudo de 100 casos. Rev Col Bras Cir 2008;35(4):235-43.

\section{Correspondence to:}

Carlos Augusto Real Martinez

Rua Rui Barbosa, 255, ap. 32

CEP: 09190-370 - Santo André (SP), Brazil

E-mail: caomartinez@uol.com.br 